Article

\title{
Biocide Use in the Beverage Industry: Consumers' Knowledge and Label Preferences Relating to the Need and Usefulness of Biocides with Particular Reference to Dairy Beverage Products in New Zealand and China
}

\author{
Lei Cong ${ }^{1,2} \mathbb{D}$, Phil Bremer ${ }^{1,3,4} \mathbb{D}$, Eddy Fang ${ }^{4,5}$, Linling Li $^{5}$ and Miranda Mirosa $1,3,4, *(\mathbb{D})$ \\ 1 Department of Food Science, University of Otago, Dunedin 9054, New Zealand; lei.cong@lincoln.ac.nz (L.C.); \\ phil.bremer@otago.ac.nz (P.B.) \\ 2 Department of Agribusiness and Markets, Lincoln University, Lincoln 7647, New Zealand \\ 3 New Zealand Food Safety Science Research Centre, Massey University, Palmerston North 4474, New Zealand \\ 4 New Zealand-China Food Protection Network, Massey University, Palmerston North 4474, New Zealand; \\ Eddy.Fang@xjtlu.edu.cn \\ 5 International Business School Suzhou, Xi'an Jiaotong-Liverpool University, Suzhou 215000, China; \\ linling.li17@outlook.com \\ * Correspondence: miranda.mirosa@otago.ac.nz; Tel.: +64-3-479-7953
}

Citation: Cong, L.; Bremer, P.; Fang, E.; Li, L.; Mirosa, M. Biocide Use in the Beverage Industry: Consumers' Knowledge and Label Preferences Relating to the Need and Usefulness of Biocides with Particular Reference to Dairy Beverage Products in New

Zealand and China. Beverages 2022, 8 ,

5. https://doi.org/10.3390/

beverages 8010005

Academic Editor: Alessandra

Del Caro

Received: 17 December 2021

Accepted: 4 January 2022

Published: 6 January 2022

Publisher's Note: MDPI stays neutral with regard to jurisdictional claims in published maps and institutional affiliations.

Copyright: (C) 2022 by the authors. Licensee MDPI, Basel, Switzerland. This article is an open access article distributed under the terms and conditions of the Creative Commons Attribution (CC BY) license (https:// creativecommons.org/licenses/by/ $4.0 /)$.

\begin{abstract}
Biocides, in the form of sanitisers and disinfectants, are used extensively to reduce the risk of microbial contamination to beverage products and to ensure the safety of potable water used in processing. To better understand consumers' perceptions of biocide use and to explore messaging strategies regarding their importance to ensure product safety, eight focus groups were conducted in New Zealand $(n=4)$ and China $(n=4)$. Consumers generally did not understand why or how biocides were used. In both countries, their most trustworthy source of information on biocide use was government sources. New Zealand and Chinese participants did not like the word "biocide" mentioned on labels due to its perceived negative connotations. Interestingly, acceptance for the word was higher if the phrase "environmentally friendly" was simultaneously communicated. The findings from this study have provided the beverage industry with guidance on how best to initiate conversations with consumers on the use of biocides.
\end{abstract}

Keywords: Asia Pacific; functional foods; functional beverages; new product development

\section{Introduction}

In the dairy and other food and beverage industries, the use of disinfectants and sanitisers are integral to the production of safe products, as they reduce the risk of foodborne disease by inhibiting pathogenic microorganisms present on product contact surfaces and by ensuring the safety of potable water used either in production or for the rinsing down of surfaces [1]. Sanitisers can be broadly grouped into being either oxidising agents or surface-active compounds. Halogen-based (e.g., chlorine) compounds, peracetic acid (PAA), ozone, and hydrogen peroxide are examples of oxidising agents, while acid anionic compounds and quaternary ammonium compounds (QACs) are examples of surface active compounds [1-3]. Chlorine is the disinfectant most generally used to ensure the safety of potable water supplies [4].

Owing to their ability to kill microorganisms, disinfectants and sanitisers are frequently given the generic term biocides. In processing plants and for water disinfection the use of biocides is tightly regulated. Only approved biocides can be used in processing plants, and their maximum use concentration is specified for both food and non-food contact surfaces. In addition, the use of biocides on food contact surfaces usually occurs at times when the product is not present. Nevertheless, residues in water or on product contact surfaces may 
potentially come in contact with the product resulting in low levels of biocides or their breakdown products being detectable in the final product [5].

For example, chlorine-based (e.g., calcium or sodium hypochlorite) sanitisers are commonly used on farms, in processing plants, and in municipal supplies for ensuring the safety of potable water, as well as in food or beverage processing plants to sanitise surfaces. While chlorine plays a crucial role in helping to produce safe foods and beverages, the occurrence of chlorinated residues (chlorates and perchlorates) that have been generated as by-products of chlorine use has raised concerns with food regulatory bodies owing to their potential to inhibit iodine uptake or to cause acute methaemoglobin [6]. These concerns has resulted in the EU mandating a reduction in the allowable maximum residue levels for chlorates and perchlorates $[7,8]$ in foods and beverages to such an extent that production practices throughout entire production chains are likely to be affected [9].

As regulatory interest in biocide use has increased, interest has also increased in understanding consumers' perceptions about their use in food or beverage processing facilities, because consumer attitudes are known to play an important role in influencing policy making and product demand [10].

To determine what information existed on consumer perceptions of biocide use in food production and the drivers for those perceptions, a review of the literature was conducted, with the research questions that underpinned the review being:

(a) How aware are consumers about biocide usage in the food industry?

(b) Do consumers link health impacts with the presence of biocide residue in food products, especially dairy products?

(c) Do concerns about biocide residue in food (dairy) products influence consumers' willingness to pay?

The databases searched were Web of Science Core Collection and Scopus. Keywords used in the review included biocide, disinfect*, sanitis*, clean*, maintenance compounds, hygiene, AND consum*, perception, acceptance, concern*, AND food, beverage, dairy, water.

Other than a few articles assessing water quality that focused on the taste associated with water disinfection, which were deemed out of scope given there was little or no mention of risk or risk perception, only three relevant articles were found. The first of these was a study exploring 739 women's knowledge of water sources and sewage treatment in Mérida, Mexico, and the effect of environmental awareness on perceived environmental and health risks related to household cleaning products [11]. The paper reported that the woman surveyed were unaware of the city's water management system. Further, there was a positive and statistically significant association between risk perception and environmental awareness, education level, and employment status. The authors recommended the development of education and risk communication strategies to inform residents of the health and environmental risks associated with cleaning agents.

The second study examined a change in water consumption and its potential influential factors in Shanghai [12]. This study surveyed 416 residents in Shanghai and results revealed that there was a strong correlation between health belief (status) and drinking water choice. Age, personal income, education, housing condition, and risk perception also impacted on choice. Drinking water-related diarrhoea was found to be associated with all types of water, and improper water hygiene behaviours occurred. Interestingly, $52 \%$ of respondents though that tap water was the safest choice, with only $13 \%$ reporting bottled water as being the safest. The following two questions were asked in the survey: Do you know the reason why we need to chlorinate our water? and Have you ever heard of disinfection by-products? However, the answers to these questions were not reported. The authors concluded that the administrative department (sic) should provide related health education to safeguard public health in accordance with various drinking water choices.

The third relevant study was a community-based exploratory study in Newfoundland, Canada, where 100 households across 45 communities in Newfoundland were surveyed to examine their perceptions of drinking water quality [13]. The public water quality reports on the water from the same communities over a 23 -year period were also obtained. Older, 
better educated, and higher-income respondents were more satisfied with water quality than the younger, less educated, and lower-income group respondents. There was no association between the level of satisfaction and the actual quality of the water. The presence of disinfection by-products (DBPs) was the most important water quality (contaminant) issue. The authors postulated that regular media coverage on water chlorination may have impacted on the public's perception of water chlorination and its threat to health, despite the provincial government clearly stating that the benefits of water chlorination and the health risks from micro-organisms far outweighed the risks from DBPs. The authors stated "Probably, the government message has failed to reach the community and therefore cancer has emerged as the most important perceived health risk". The authors concluded that there is an existing disconnect between public perception of drinking water quality and actual quality, and that a means needs to be developed to reach out to communities and disseminate the information on water quality in a more user-friendly way. Simply uploading reports in websites may not suffice to educate people.

In summary, no articles to date have specifically focused on consumers' perceptions of sanitiser use in food or beverage processing plants. Given the paucity of extant information on the topic, it made sense to conduct primary research to better understand consumer perceptions of biocide usage.

In the wider consumer behaviour literature, there is evidence that shows that information available to consumers can have a significant effect on their purchase decision making [14-16], with more specific research conducted through delivering information by product labels. For example, consumers in Des Moines and Harrisburg, USA, were willing to pay more for intragenic labels with enhanced nutrition, compared with conventional plain labels [17]. However, a range of studies have indicated that consumers have limited understanding of some of the information presented on food or beverage labels [18,19]. Thus, the current study aims to explore consumers' preferences in terms of beverage labels containing biocide-related information in order to better understand how to initiate conversations with consumers on the use of biocides in food or beverage processing.

Consumers from either New Zealand or China were selected for this study as a comparison between western and eastern society perceptions. From the literature, there is a significant public concern about food safety in China $[20,21]$. Historically, the Chinese food industry has suffered from numerous highly publicised scandals, including the presence of melamine in milk-based foods produced in China in 2008 and 2010, and the avian influenza A (H7N9) (poultry) outbreak in 2013 [22]. In several instances, the social behaviour in China in relation to food safety issues has even exhibited the features of collective panic, which are characterised as emergent collective phenomena that are wholly or mostly unorganised [20]. One remarkable case was that after the melamine in milk incident in 2008, milk demand over the subsequent decade was mostly met by imports [23].

Therefore, the current study focuses on two key questions:

- Firstly, what is consumers' current knowledge about, and what are their most trustworthy information sources for, the use of biocides in the production and processing of food or beverages?

- Secondly, can information be delivered through packaging labels to positively influence consumers' attitudes towards the use of biocides?

\section{Materials and Methods}

Focus group sessions were conducted in NZ (Auckland, $n=2$, Dunedin, $n=2$ ) and China (Suzhou, $n=4$ ), allowing for cross-cultural differences in consumer perceptions to be examined. Importantly, given the well-documented mistrust of the Chinese locally produced dairy beverages [24,25], and the obvious advantage to the NZ dairy industry in understanding consumer perceptions in this key export market, the decision was made to ask Chinese participants to answer all questions about purchases for imported foods from developed countries, such as US, Germany, Australia, and NZ, but not from China. 
This project was approved by the University's Human Ethics Committee (project number 18/025).

\subsection{Design of the Moderator Guide}

Focus groups are particularly useful when trying to understand consumers' perceptions and feelings about a particular issue, product, service, or idea [26,27] and generate a rich understanding of participants' experiences and beliefs [28,29]. For example, focus groups are widely applied in food industry to explore consumers' label preferences [29-31]. In addition, focus groups are especially useful to combine with methodologies such as choice experiment [31,32] and sensory tests [32,33], to explore a topic, or collect group languages or narratives.

Thus, the focus group moderator's guide was separated into two parts (Figure 1). In the first part, the moderator asked participants to briefly state what knowledge they had of biocide use in the beverage industry. The moderator then defined what a biocide was (Figure A1 of Attachment), and participants discussed where they would potentially go to get information about biocides. The second part aimed to outline participants' preference for labels presenting information relevant to the use of biocides during food or beverage processing. Participants were asked to make a series of choices between two products displayed on a slide (an example can be found in Figure A2 of Attachments), which were equal in all attributes, except the label information. The products were two cartons of UHT (ultra-high temperature processing) milk which were identical except for the addition of a sticker outlining some additional information.

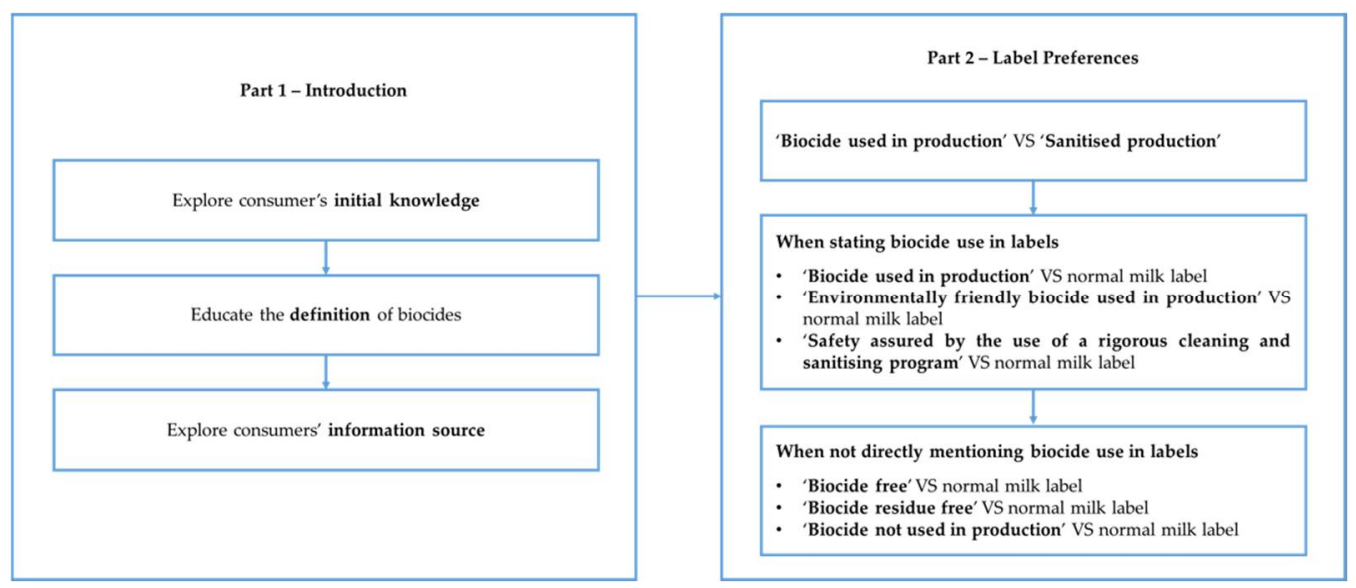

Figure 1. Flow chart of focus group process.

\subsection{Participants}

Only people aged over 18 and who did NOT work in the food industry or had not studied food-related subjects were selected for this study. The aim of the sampling strategy was to match samples in NZ and China as closely as possible. Given the interest in Chinese consumers that have the ability to purchase imported beverages, the decision was made to set a preferential income criterion at an above average salary level. Moreover, given that past literature has shown that people with children living at home are more concerned about food safety-related risks, parents with children at home were purposefully included in the study where possible. Therefore, participants who met the following requirements were preferentially selected:

- $\quad$ People aged between 30 and 60;

- People who have a combined household income greater than the average (NZD 104,000 annually in NZ [34], CNY 15,000 monthly in China) ${ }^{1}$;

- Parents who have at least one child living with them at home. 
In total, 37 participants were recruited for the study in NZ and 30 were recruited in China. More female than male participants were recruited (approx. rate in NZ, F/M $\approx 3 / 2$; approx. rate in China, $\mathrm{F} / \mathrm{M} \approx 5: 1)$. The gender split was considered to be acceptable.

\subsection{Conduct of Focus Group Sessions}

Focus group sessions in NZ were conducted in English by a researcher from the University of Otago and moderated by another research team member. Focus group discussions were then transcribed into text for further analysis.

Focus group sessions in China were conducted in Chinese by the research team from the collaborating institute, Xi'an Jiaotong-Liverpool University. All translated documents were proofread and verified for accuracy by two Chinese postgraduate students studying at the University of Otago who are native speakers of Mandarin and had been living in New Zealand for more than two years. To ensure consistency of these cross-cultural sessions, a Chinese-speaking researcher from the University of Otago joined in the sessions in China using the conferencing software Zoom. Focus group discussions were then transcribed into text in Chinese and translated into English for further analysis.

The sessions were piloted with a group of students in both NZ and in China, and the moderator guide was modified accordingly before starting the actual focus group sessions.

\section{Results}

\subsection{Consumers' Knowledge and Trustworthy Information Source}

\subsubsection{Consumers' Knowledge about Using Biocides}

The vast majority $(60 / 67)$ of participants indicated that they had never considered biocide use in the beverage industry. Participants, both from NZ and China, had no clear understanding of what types of biocides beverage plants would use for cleaning and sanitising, as the following quotes explained: "I know that they do clean, but what cleaning agents? (do) Not really (know), to be very honest." (NZFG2, M); "The simplest point of view may be using high temperature sterilization, and I never think about any chemical stuff." (CHFG1, F).

Where there was some knowledge about biocide use, it was obtained from several sources, including:

- Friends in the industry - four participants from NZ and one from China mentioned they had friends who worked in the industry and their friends had shared some working experiences;

- Factory tour-one participant from NZ had obtained some knowledge when he attended a tour of a dairy plant;

- TV programmes-one participant from NZ and one from China mentioned learning relevant information from a TV programme.

\subsubsection{NZ Consumers' Information Source about Using Biocides}

NZ participants considered the best way to find information regarding the benefits or risks of using biocides to be internet searching, as illustrated by the following quote-"Just Google and go through different websites, isn't that where everyone looks?" (NZFG1, F). Online searching was considered to be able to provide multiple information sources such as:

- Government-related information-websites or regulations;

- Manufacturer-related information-websites;

- Educational institution-related information-academic paper or reports;

- Independent organisation-related information-reports.

Few participants mentioned the TV or suggestions from friends/families as sources of information. However, for NZ participants, there was no clear preference for information sources. It was considered that when searching online, information from multiple sources is obtained, so that "you believe what you want to believe ... " (NZFG4, F). Therefore, typically participants indicated that they would look at a variety of sources-"I will just search things 
out, do peer review, look at a range of sources, read papers on that and then make my own mind up about it." (NZFG4, F).

For NZ participants, the most trustworthy information source was considered to be government-related information, followed by independent organisation-related and educational institution-related information. Information issued from manufacturers was considered the least credible, but did receive some support.

\subsubsection{Chinese Consumers' Information Source about Using Biocides}

In China, the information sources participants would use to find information regarding the benefits or risks of using biocides included:

- Government-related information-TV, newspaper, We-Media (such as the public account of official organisations in Weibo or WeChat), websites or regulations;

- Educational institution-related information-academic paper or reports;

- Independent organisation-related information-reports;

- $\quad$ Friends or professionals.

Most Chinese participants considered government-related information to be the most trustworthy. CCTV (China Central Television) and other governmental TV channels also had high credibility among participants, and academic papers or reports were also believed to be reliable. Since WeChat is a very popular social media channel in China, the moderator asked participants their opinions of information diffused through WeChat. It was interesting to note that information on WeChat was not considered to be reliable, as explained by the quote- "I trust information from authoritative media, such as CCTV news. I don't trust information on WeChat which lacks scientific basis." (CNFG3, Role 3).

\subsection{Label Preferences}

\subsection{1. "Biocide Used in Production" vs. "Sanitised Production"}

In a second exercise, participants were asked to choose between two cartons of UHT milk which were identical except for the addition of a sticker on one of them which provided some additional information. When participants were asked to choose from option A labelling "Biocide used in production" and option B stating "Sanitised production", most participants in both NZ (73\%) and China (80\%) indicated that they would choose option B over option A. According to participants, there were two reasons for their choice:

- 'Biocide' was perceived as being a negative word: "Because biocide sounds like something bad like a pesticide of something to me. Sanitised sounds clean." (NZFG2, F);

- 'Biocide' was also an unfamiliar word: "People tend to go for what they know, until today I wouldn't have known what biocides is." (NZFG 4,F)

\subsubsection{Consumers' Label Preferences When Stating Biocide Use}

In a further trial, participants were asked to choose between two cartons of UHT milk, and this time, in all cases, Option A was a normal carton of milk and option B contained the label with the additional information ("biocide used in production", "environmentally friendly biocide used in production", or "safety assured by the use of a rigorous cleaning and sanitising program"').

Very few NZ participants ( $8 \%$ ) selected the milk cartoon containing the label "biocide used in production (Figure 2), as 'biocide use' was perceived to hold negative connotations. For example, participants mentioned "Anything with 'cide' isn't good. It is a negative connotation to it." (NZFG4, F), and also that "If there is something on the label, you kind of think that it is there as it is a concern" (NZFG2, F). Another reason given for selecting the milk cartoon which did not mention information about biocide was that NZers felt that they did not need too much information, since the safety of dairy products was high- "I don't need a label to tell me the beverage is safe. I trust the brand. I have never got sick from drinking milk in $N Z$, the whole system is trustworthy. NZ-made makes a difference. Wouldn't necessarily mean a brand." (NZFG1, M). 
Surprisingly when the label read "environmentally friendly biocide used in production", 57\% of NZ participants selected it over the cartoon without any additional label. In addition, participants in NZ had no clear preference for the label regarding "Safety assured by the use of a rigorous cleaning and sanitising programme".

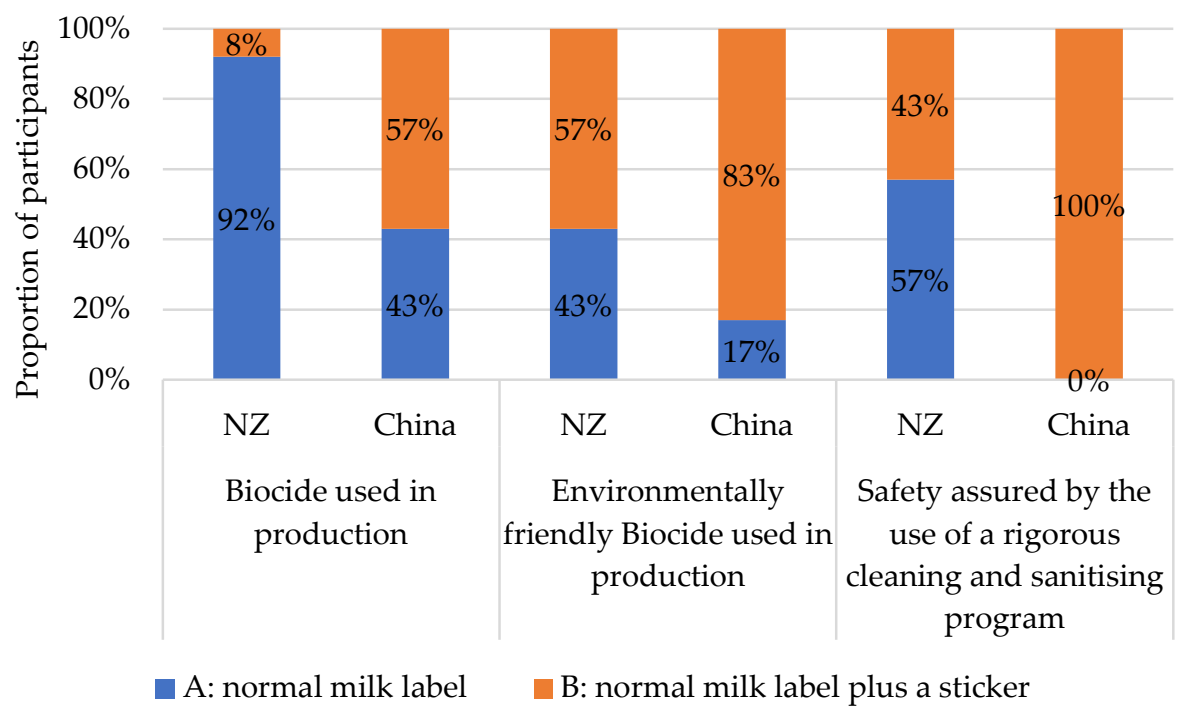

Figure 2. Participants' label preferences when products' production processes involve the use of biocides.

In contrast with the NZ participants, slightly more than half (57\%) of the Chinese participants indicated that they would choose the label stating "biocides used in production" (Figure 2), as one participant explained: "... I have to choose product B. Because biocide usage has been indicated on the label of this product. This label information helps me know its production process more." (CNFG4, Role 1). However, $43 \%$ of participants rejected the biocide label, because they trusted products sold in the supermarket and did not like unfamiliar information mentioned on the label-" ... Let's assume that biocide is wholly a new concept to us. When I see "biocide used" on the label, I will think this may be a specific sterilization product and I will search information about its benefit and risk in Baidu. Actually this is quite troublesome for me to spend time searching information for a product. Finally, I will not buy product B." (CNFG3, Role 7).

As was reported for NZ, Chinese participants' acceptance of biocide use improved significantly if "environmentally friendly biocide" was mentioned on the label. In comparison to NZ, interestingly all participants in China preferred the label stating "safety assured by the use of a rigorous cleaning and sanitising programme", as the following quotes explain: "Label information on product B makes us feel that this product is safe." (CNFG4, Role 3), and "I choose B. This labelled information sounds more believable, because of the word on the label-rigorous." (CNFG3, Role 1).

\subsubsection{Consumers' Label Preferences When Not Directly Mentioning Biocide Use}

In the third trial, participants were asked to choose between two cartons of UHT milk which were identical except for the addition of a sticker on one of them which provided some additional information, which this time was "biocide free", "biocide residue free", or "biocides not used in production".

NZ participants appeared to have no clear label preferences when the product was stated as not containing biocide (residues), as showed in Figure 3. Participants showed their confidence about beverage safety in NZ, for example one participant explained: "I do not care if its biocide free or not... I am fairly confident if it's in the store, it would not make you sick ..." (NZFG1, F), and another one said "Unless there is a national news event, someone's got really sick because of it. Without a heightened awareness, I won't care..." (NZFG4, F). 


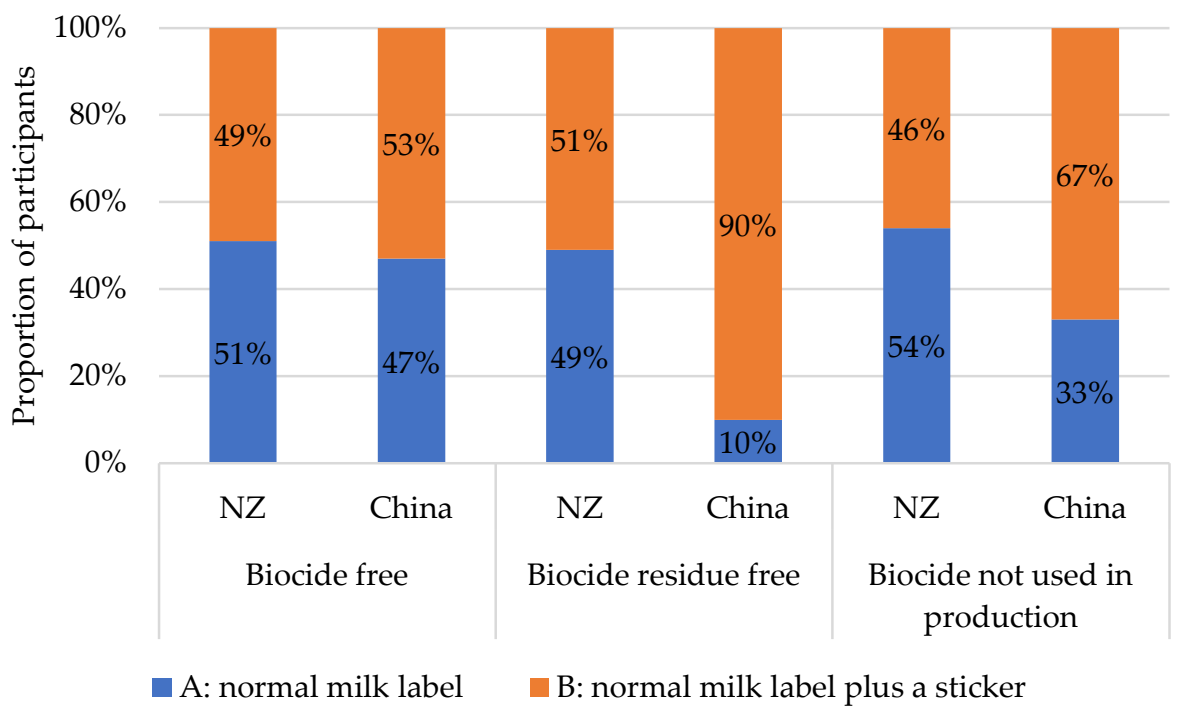

Figure 3. Participants' label preferences when biocide use is not directly mentioned on the label.

Chinese participants only slightly preferred the "biocide free" label (53\%) or the "biocide not used in production" (67\%) label (Figure 3), as some participants understood the importance of biocides being used in the production process-"I choose A. As far as I know, biocides must be used in milk products. Label of product A indicated nothing about biocides. But I tend to think that biocides have already been used to remove bacteria of product A. Label on product B indicated "biocide free", it is quite weird for me to see this label." (CNFG2, Role 7). Interestingly, Chinese participants (90\%) preferred the label containing the wording "free", as stated by the following quote: "When we choose milk product, "free" on label of one product will leave favourable impression on consumers. Consumers tend to believe this product is quite safe." (CNFG3, Role 2).

\section{Discussion}

Despite the fact that biocides, in the form of sanitisers and cleaners, are used extensively in food and beverage processing, generally, consumers in both NZ and China had not previously thought about their use and did not have a clear understanding about what types of biocides processing plants would use. This result revealed the lack of consumer perception on this topic. When promoted to think about biocide use, a number of participants expressed initial concern. Generally, NZ participants did not like the wording "biocide" mentioned on labels due to its negative connotation related to chemical residues. For example, although Chinese consumers tended to read detailed labels that described the production process, compared with the label stating "safety assured by the use of a rigorous cleaning and sanitising programme", the acceptance of labels mentioning biocide was still much lower. This reflected an existing scientific consensus in the psychological field-positive-negative asymmetry, which can be explained as negative messages being easier to receive and remember than positive ones $[35,36]$. Since "biocide" was perceived as a negative word, regardless of how little people knew about biocide use, most consumers instinctively felt repulsed. Thus, it is suggested that food companies should look at explaining the positive connections between biocide use and food safety. In the meantime, governmental authorities could look to play a role of communicating information about the importance of biocide use to consumers if public and regulatory scrutiny increases.

One surprising exception was that the preference for labels not mentioning the biocides was that the label stating "environmentally friendly biocide" gained higher acceptance than no mention of biocide at all. Several studies have examined the positive influence of consumers' perceptions regarding a series of products or services (e.g., food, clothes, luxury hotel, etc.) by communicating environmentally friendly messages. For example, a recent focus group study in Spain reported the positive attitude shown by consumers to products 
containing labels reporting sustainability attributes [37]. In a questionnaire involving 343 college students in the US, it was shown that respondents formed positive attitudes toward an apparel brand when the advertising message contained explicit information about environmentally friendly products [38]. Research conducted in 2020 by Sahin, Baloglu and Topcuoglu suggested that luxury hotels could increase the effectiveness of their advertising strategies by mentioning their green certification [39]. Providing environmentally friendly messages allows consumers to take into account environmental and ethical considerations when making purchase choices. Producers can leverage this finding by communicating risks to the public with environmentally friendly messages.

Since the age range of the respondents was from 30-60, it means that participants fall into the two generation groups-Generation X, with birth dates ranging from 1961-1981 [40], and Generation Y, also referred as Millenniums or Millennials, who were born between 1980-2000 [41]. Although consumers' sustainable consumption has developed gradually over the last two decades [42,43], it is interesting to note that multigroup analysis revealed the impact of corporate environmental responsibility on customer loyalty is significantly higher within Generation Y compared with Generation X [44]. This may lead dairy companies to tailor their information channel to better communicate biocide use and environmental efforts with Generation $Y$, which is considered as the most influential consumer group in the world [41]. For example, as millennials are technology-oriented and highly exposed to social influence, they tend to attach more importance to environmental messages that are communicated within their social networks [41,45], companies are advised to communicate their sustainability initiatives through social media, e.g., posts and blogs, to encourage consumers' engagement of understanding the benefits of using biocides, especially environmentally friendly ones, in beverage production.

Generally, beverages, especially dairy beverages, and their production processes were perceived as having high credibility in developed countries. It is commonly known that NZ has a good reputation for its food and beverages and production systems. Chinese consumers generally consider NZ as having strict food and beverage standards and government supervision, and were willing to pay a premium to buy UHT milk from NZ compared to Australia, Germany, and France [46]. In contrast, Chinese participants showed less confidence with China's regulations than those in developed counties. This is not surprising, given that Chinese consumers tend to be sensitive about any risks that may exist in their food systems due to several well-documented food scares [18,22]. In several instances, social behaviour in China in relation to food safety issues has even exhibited the features of collective panic, which are characterised as emergent collective phenomena that are wholly or mostly unorganised [20]. Therefore, in line with previous research, when talking about label preferences in the current study, wordings such as "free" or "rigorous" were perceived positively by Chinese consumers.

\section{Conclusions}

In summary, due to a lack of awareness and understanding about how food or beverages are processed, consumers generally do not think about biocide use. When prompted to do so, generally, participants did not like the wording "biocide" mentioned on labels due to its negative connotation to a chemical residue. However, if biocide use comes under public scrutiny and therefore needs to be addressed by the beverage industry, companies will be forced to respond. In this case, compared with directly stating biocide use, participants showed better acceptance if the wording "environmentally friendly" was communicated at the same time.

Consumers from both countries trusted regulatory agencies to provide information about biocides, and the fact that there are, for many sanitisers and disinfectants, no government regulatory maximum residue standards could be problematic for consumers. Unless acted upon, the current void in information about allowable residues in beverages, risks being filled by misinformation on social media by consumers and particular interest groups with specific agendas. In addition, educational institution-related information and inde- 
pendent organisation-related information were also perceived as reliable by participants in both countries.

Although NZ dairy products are thought to be highly credible by both NZ and Chinese consumers, given the probability that biocide use could be picked up in markets as a concern, companies would be wise to further investigate further how best to portray biocide use in a favourable light in their key markets.

\section{Limitations and Future Research}

Through investigating consumers' knowledge and label preferences regarding biocide use in the beverage industry, this study provides a first attempt to explore consumers' perceptions in this area.

Our review of the literature revealed that there were no articles which specifically focused on consumers' perceptions of biocide use in food or beverage processing plants. However, while the scope of this literature was focused purely on consumers' perceptions pertaining to biocide use, there is of course relevant indirect informative literature on related topics, such as consumers' subjective risk judgments for a range of food safety hazards. This may include, but is not limited to, topic areas such as perceived risks from pesticides, pathogens, natural toxins, etc. A wider review of such literature might reveal preferences, for example, of consumers' willingness to pay for fresh produce that is certified as free of pesticide residues. Results gleaned from literatures such as these could potentially be of value and a future review of consumers more general risk perceptions relating to food or beverage processing is therefore recommended.

Given that the obvious benefits of using biocides conflict with the fact that their use is perceived as a potential risk by consumers, it is going to be critical for regulators and industry stakeholders to find effective ways to educate consumers on why biocide use is important to ensure food safety. As such, evidence-based research that can underpin the design of successful risk communication initiatives would be worthwhile. As an example, future work could build on this study by employing Kahneman and Tversky's prospect theory [47] to further explore the framing effect in more detail. Researchers could compare how information about biocide use is received by consumers when it is presented in a range of different framing scenarios (e.g., 'risk choice', 'attribute', or 'goal orientated'). While the qualitative nature of this study enables an in-depth understanding of consumers' perceptions to be obtained, owing to the small sample size, these perceptions may not necessarily reflect all of the perceptions of the entire population of interest. In order to further investigate consumers' preferences and willingness to pay for products with specific attributes and to provide more generalizable data, future research should be conducted using quantitative approaches applicable for larger sample sizes such as surveys or questionnaires. Additionally, it is worth investigating behavioural biometric approaches such as eye-tracking technologies, the measurement of skin-conductance and heart rate and the use of facial emotion-recognition software, which could be used to gain a better understanding of consumer's subconscious behaviour in relation to biocide use when faced with apparently "real-life" food-related decision making. By better understanding emotional reactions that are not affected by higher cognitive processes, for example, these experimental approaches would enable researchers to advise those educating consumers on biocide use on how to increase the effectiveness of their communications.

In summary, companies would be wise to further investigate further how best to portray biocide use in a favourable light in their key markets. This includes obtaining an understanding of not just what to say, but also how best to frame this message and also what channels to use to communicate this information to ensure it is perceived as being credible. 
Author Contributions: Methodology-M.M., P.B., E.F. and L.C.; Writing-original draft preparation, L.C.; writing-review and editing, P.B. and M.M.; Data collection-in New Zealand, L.C., P.B. and M.M. In China, E.F. and L.L. All authors have read and agreed to the published version of the manuscript.

Funding: This research was funded by New Zealand Food Safety Science Research Centre (NZFSSRC), 3000030638.

Institutional Review Board Statement: The study was approved on the 5 March 2018 by the Ethics Committee of University of Otago (protocol code 18/025).

Informed Consent Statement: Informed consent was obtained from all subjects involved in the study.

Conflicts of Interest: The authors declare no conflict of interest.

\section{Appendix A}

\section{-- Definition of BIOCIDES in this project ---}

- Disinfectant or sanitising compounds, including water disinfectants, that are either used to clean and sterilise food processing areas or added to water to make it clean and suitable for use in food processing plants.

- These biocides are therefore not directly added to food but may be inadvertently present in foods.

- Currently in NZ the occurrence of residues from such biocides in foods is not specifically regulated.

- For the purpose of the current study, biocides do not include preservatives, insecticides and other pesticides (herbicides, fungicides, rodenticides, etc.).

\section{--- Examples of using biocides ---}

- In the dairy industry, teat sanitising may be carried out by using chemical-based sanitisers.
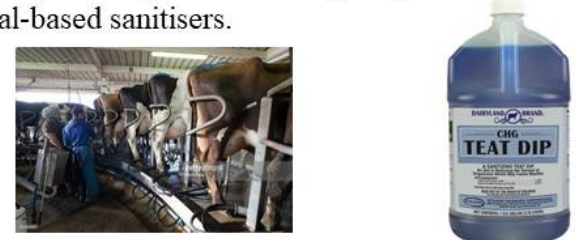

- Pipes and tanks used for dairy processing are cleaned using chemical sanitising products.
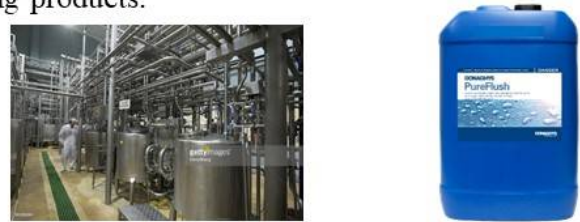

- Cut bagged vegetable, which you can buy from the supermarket, is washed in water that contains biocides.

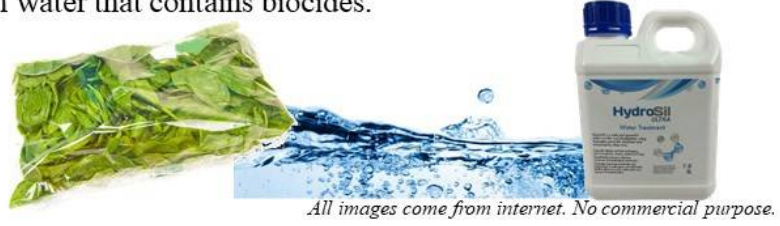

Figure A1. A slide providing information on the definition of Biocides and examples of biocides used in the food industry as well as examples of what they may be used for. This slide was used to introduce biocides to the focus group participants in NZ. The corresponding slide used in China was translated into Chinese. 


\section{Which One Would You Choose?}

A

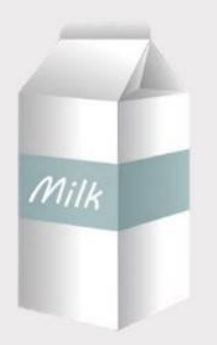

B

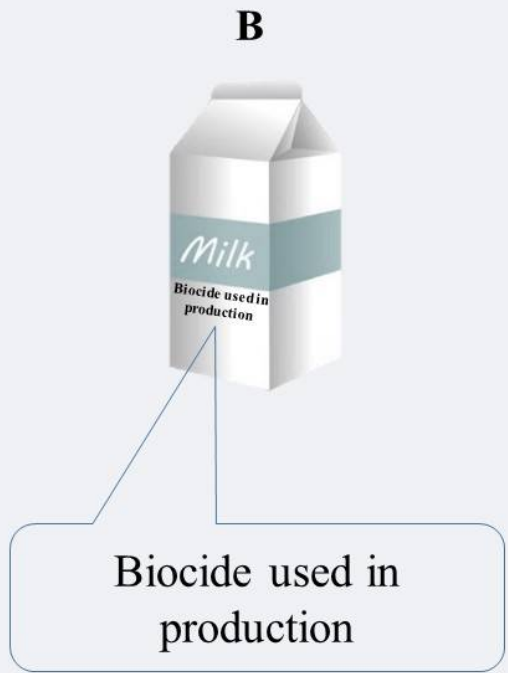

Figure A2. Example of the slides utilised in the focus groups sessions to collect label preference.

\section{Notes}

$1 \$ 104,000$ is the NZ average annual household income according to the Stats NZ 2017. Given income is discussed as a monthly rather than annual figure in China, the equivalent monthly figure was used for screening participants instead.

\section{References}

1. Maddox, I.S. Practical Sanitation in the Food Industry; CRC Press: Boca Raton, FL, USA, 2020.

2. Stanga, M. Sanitation: Cleaning and Disinfection in the Food Industry; John Wiley \& Sons: Hoboken, NJ, USA, 2010.

3. Teh, K.H.; Flint, S.; Brooks, J.; Knight, G. Biofilms in the Dairy Industry; Wiley Blackwell: New York, NY, USA, 2015.

4. Collivignarelli, M.C.; Abbà, A.; Benigna, I.; Sorlini, S.; Torretta, V. Overview of the main disinfection processes for wastewater and drinking water treatment plants. Sustainability 2018, 10, 86. [CrossRef]

5. World Health Organization. Benefits and risks of the use of chlorine-containing disinfectants in food production and food processing. In Proceedings of the Report of a Joint FAO/WHO Expert Meeting, Ann Arbor, MI, USA, 27-30 May 2008.

6. EFSA Panel on Contaminants in the Food Chain. Risks for public health related to the presence of chlorate in food. EFSA J. 2015, 13, 4135 .

7. European Union. Commission Regulation (EU) 2020/749 of 4 June 2020 amending Annex III to Regulation (EC) No $396 / 2005$ of the European Parliament and of the Council as regards maximum residue levels for chlorate in or on certain products. Off. J. Eur. Union 2020, 178, 7-20.

8. European Union. Commission regulation (EU) 2020/685 of 20 May 2020. Amending Regulation (EC) No 1881/2006 as regards maximum levels of perchlorate in certain foods. Off. J. Eur. Union 2020, 160, 3-5.

9. McCarthy, W.P.; O'Callaghan, T.F.; Danahar, M.; Gleeson, D.; O'Connor, C.; Fenelon, M.A.; Tobin, J.T. Chlorate and other oxychlorine contaminants within the dairy supply chain. Compr. Rev. Food Sci. Food Saf. 2018, 17, 1561-1575. [CrossRef] [PubMed]

10. Guiné, R.P.F.; Florença, S.G.; Barroca, M.J.; Anjos, O. The link between the consumer and the innovations in food product development. Foods 2020, 9, 1317. [CrossRef]

11. Martínez-Peña, R.M.; Hoogesteijn, A.L.; Rothenberg, S.J.; Cervera-Montejano, M.D.; Pacheco-Ávila, J.G. Cleaning products, environmental awareness and risk perception in Mérida, Mexico. PLoS ONE 2013, 8, e74352. [CrossRef]

12. Chen, H.; Zhang, Y.; Ma, L.; Liu, F.; Zheng, W.; Shen, Q.; Zhang, H.; Wei, X.; Tian, D.; He, G. Change of water consumption and its potential influential factors in Shanghai: A cross-sectional study. BMC Public Health 2012, 12, 1-9. [CrossRef]

13. Ochoo, B.; Valcour, J.; Sarkar, A. Association between perceptions of public drinking water quality and actual drinking water quality: A community-based exploratory study in Newfoundland (Canada). Environ. Res. 2017, 159, 435-443. [CrossRef]

14. Bruhn, C.; Bruhn, J.; Cotter, A.; Garrett, C.; Klenk, M.; Powell, C.; Stanford, G.; Steinbring, Y.; West, E. Consumer attitudes toward use of probiotic cultures. J. Food Sci. 2002, 67, 1969-1972. [CrossRef]

15. Karim, A.M.; Nasouddin, S.; Othman, M.; Adzahan, M.N.; Hussin, S. Consumers' knowledge and perception towards Melicope ptelefolia (Daun Tenggek Burung): A preliminary qualitative study. Int. Food Res. J. 2011, 18, 1481. 
16. Xing, D. Survey and Analssis of the current Consuming Situation and the Quality Administration of the Health-Care Food; Shanxi Medical University: Shanxi, China, 2011.

17. Colson, G.; Huffman, W.E. Consumers' willingness to pay for genetically modified foods with product-enhancing nutritional attributes. Am. J. Agric. Econ. 2011, 93, 358-363. [CrossRef]

18. Cong, L.; Mirosa, M.; Kaye-Blake, W.; Bremer, P. Ideal attributes of functional foods helping the immune system recover from the impact of air pollution: A consumer-led product design. J. Int. Food Agribus. Mark. 2020, 32, 482-502. [CrossRef]

19. Liu, R.; Pieniak, Z.; Verbeke, W. Consumers' attitudes and behaviour towards safe food in China: A review. Food Control 2013, 33, 93-104. [CrossRef]

20. Desmarchelier, B.; Fang, E.S. Social media and the diffusion of information: A computational experiment on the emergence of food scares. Kyklos 2016, 69, 559-583. [CrossRef]

21. Liu, H.-B.; McCarthy, B.; Chen, T. Green food consumption in China: Segmentation based on attitudes toward food safety. J. Int. Food Agribus. Mark. 2016, 28, 346-362. [CrossRef]

22. Yu, J.; Qiao, J. Consumer concern about food safety and its impact on their familiarity with food traceability systems in china. J. Int. Food Agribus. Mark. 2017, 29, 16-28. [CrossRef]

23. Inouye, A.; Anderson, L. China: Dairy and Products Annual; USDA Foreign Agricultural Service: Washington, DC, USA, 2017.

24. El Benni, N.; Stolz, H.; Home, R.; Kendall, H.; Kuznesof, S.; Clark, B.; Dean, M.; Brereton, P.; Frewer, L.J.; Chan, M.Y.; et al. Product attributes and consumer attitudes affecting the preferences for infant milk formula in China-A latent class approach. Food Qual. Prefer. 2019, 71, 25-33. [CrossRef]

25. Zhou, Y.; Wang, E. Urban consumers' attitudes towards the safety of milk powder after the melamine scandal in 2008 and the factors influencing the attitudes. China Agric. Econ. Rev. 2011, 3, 101-111. [CrossRef]

26. Beaudin, C.L.; Pelletier, L.R. Consumer-based research: Using focus groups as a method for evaluating quality of care. J. Nurs. Care Qual. 1996, 10, 28-33. [CrossRef] [PubMed]

27. Krueger, R.A. Focus Groups: A Practical Guide for Applied Research; Sage Publications: Thousand Oaks, CA, USA, 2014.

28. Morgan, D.L.; Krueger, R.A. The Focus Group Guidebook; Sage Publications: Thousand Oaks, CA, USA, 1998.

29. Banovic, M.; Arvola, A.; Pennanen, K.; Duta, D.E.; Brückner-Gühmann, M.; Lähteenmäki, L.; Grunert, K.G. Foods with increased protein content: A qualitative study on European consumer preferences and perceptions. Appetite 2018, 125, 233-243. [CrossRef] [PubMed]

30. Emberger-Klein, A.; Menrad, K. The effect of information provision on supermarket consumers' use of and preferences for carbon labels in Germany. J. Clean. Prod. 2018, 172, 253-263. [CrossRef]

31. Sirieix, L.; Delanchy, M.; Remaud, H.; Zepeda, L. How Do Consumers React in Front of Individual and Combined Sustainable Food Labels?: A UK Focus Group Study; UMR MoISA: Montpellier Interdisciplinary Center on Sustainable Agri-Food Systems (Social and Nutritional Sciences): CIHEAM-IAMM, CIRAD, INRAE, L'Institut Agro, Montpellier SupAgro; IRD: Montpellier, France, 2011.

32. Chironi, S.; Bacarella, S.; Altamore, L.; Ingrassia, M. Quality factors influencing consumer demand for small fruit by focus group and sensory test. J. Food Prod. Mark. 2017, 23, 857-872. [CrossRef]

33. Cardinal, P.; Flores, A.; Contarini, A.; Hough, G. Focus group research on sensory language used by consumers to describe. J Sens. Stud. 2003, 18, 47-59. [CrossRef]

34. Anon. Household Income and Housing-Cost Statistics: Year Ended June 2017—Corrected. Available online: https:/ /www.stats.govt. $\mathrm{nz}$ /information-releases/household-income-and-housing-cost-statistics-year-ended-june-2017 (accessed on 30 November 2020).

35. Robinson-Riegler, G.L.; Winton, W.M. The role of conscious recollection in recognition of affective material: Evidence for positive-negative asymmetry. J. Gen. Psychol. 1996, 123, 93-104. [CrossRef]

36. Taylor, S.E. Asymmetrical effects of positive and negative events: The mobilization-minimization hypothesis. Psychol. Bull. 1991, 110, 67. [CrossRef]

37. Eldesouky, A.; Mesias, F.J.; Escribano, M. Perception of Spanish consumers towards environmentally friendly labelling in food. Int. J. Consum. Stud. 2020, 44, 64-76. [CrossRef]

38. Yan, R.-N.; Hyllegard, K.H.; Blaesi, L.F. Marketing eco-fashion: The influence of brand name and message explicitness. J. Mark. Commun. 2012, 18, 151-168. [CrossRef]

39. Sahin, S.; Baloglu, S.; Topcuoglu, E. The influence of green message types on advertising effectiveness for luxury and budget hotel segments. Cornell Hosp. Q. 2020, 61, 443-460. [CrossRef]

40. Wiedmer, T. Generations do differ: Best practices in leading traditionalists, boomers, and generations X, Y, and Z. Delta Kappa Gamma Bull. 2015, 82, 51-58.

41. Bernardes, J.P.; Ferreira, F.; Marques, A.D.; Nogueira, M. "Do as I say, not as I do"-a systematic literature review on the attitudebehaviour gap towards sustainable consumption of Generation Y. In Proceedings of the IOP Conference Series: Materials Science and Engineering, Kuala Lumpur, Malaysia, 13-14 August 2018; p. 012089.

42. Bălan, C. How does retail engage consumers in sustainable consumption? A systematic literature review. Sustainability 2021, 13, 96. [CrossRef]

43. Yue, B.; Sheng, G.; She, S.; Xu, J. Impact of consumer environmental responsibility on green consumption behavior in china: The role of environmental concern and price sensitivity. Sustainability 2020, 12, 2074. [CrossRef]

44. Moisescu, O.-I.; Gică, O.-A. The impact of environmental and social responsibility on customer loyalty: A multigroup analysis among generations X and Y. Int. J. Environ. Res. Public Health 2020, 17, 6466. [CrossRef] [PubMed] 
45. De Lenne, O.; Vandenbosch, L. Media and sustainable apparel buying intention. J. Fash. Mark. Manag. Int. J. 2017, 21 , 483-498. [CrossRef]

46. Zhang, Y.; Jin, S.; Zhang, Y.Y.; Yu, X. How country of origin influences Chinese consumers' evaluation of imported milk? China Agric. Econ. Rev. 2021, 13, 150-172. [CrossRef]

47. Kahneman, D.; Tversky, A. Prospect theory: An analysis of decision under risk. In Handbook of the Fundamentals of Financial Decision Making: Part I; World Scientific: Singapore, 2013; pp. 99-127. 